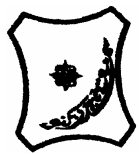

Bayero Journal of Pure and Applied Sciences, 2(2); 113 - 115

Received: July, 2009

Accepted: November, 2009

\title{
VARIANT FORMULA FOR PREDICTING PEAK EXPIRATORY FLOW RATE IN PREGNANT WOMEN IN KURA LOCAL GOVERNMENT AREA, KANO STATE, NIGERIA
}

\author{
A. I. Salisu \\ Department of Human Physiology, Faculty of Medicine, Bayero University, Kano \\ salisahmedibrahim@yahoo.co.uk;
}

\section{ABSTRACT}

Observed Peak expiratory flow rate (PEFR), Predicted and Variant PEFR values in 123 females at their reproductive ages, living in Kura local government area of Kano State, Nigeria and its environs were obtained. The prediction and variant formulae used were; PEFR $=0.36 A G E-0.47 W T+391.67$ and $K=$ mean CC $x$ mean $T L$ /mean PEFR respectively. A constant value was derived in the second formula, which was used to calculate a variant PEFR value using the individual Chest Circumference (CC) and Thoracic Length (TL) values obtained during the study period. Analysis of variance was used to compare the three different PEFR values; Observed PEFR $=375.20 \pm 3.12 \mathrm{~L} / \mathrm{min}$, Predicted PEFR = 375.05 $0.29 \mathrm{~L} / \mathrm{min}$ and Variant PEFR $=375.62 \pm 3.09 \mathrm{~L} / \mathrm{min}$ with P> 0.05. Further more, graphs were plotted to show the variation of the three values of PEFR with age in the subjects. Data for plotting the graphs were generated using the prediction and variant formulae generated from this study. The graph illustrates close association of variant formula with the observed values of PEFR obtained from the study. Variant formula may be useful in clinical setting to assess people with respiratory disorders especially asthma.

Key words: Variant formula, Peak expiratory flow rate, Pregnancy, Kura local government area

\section{INTRODUCTION}

Prediction formulae have been produced by a lot of investigators; (Elebute and Femi - Pearse, 1971; Chehreh et al., 1973; Singh et al., 1983; Gregg and Nunn, 1989; Suzanne et al., 1994; Njoku and Anah, 1999; Nku et al., 2006 and Salisu et al., 2007). These formulae are usually long and cannot easily be remembered under certain circumstances even by the authors who derived these equations. This can make the application of these equations difficult to apply in clinical setting especially when one is faced with a large number of out patients. PEFR values tend to increase with increasing age in young individuals and there is decay in PEFR values after the age of 40 years, which is faster in black Africans than Caucasians (Balchum et al., 1962). Variations in PEFR values can be explained on the basis of muscle mass, length and size of the thoracic cage, (Elebute and Femi-pearse, 1971). This forms the basis of deriving a variant formula which considers only the thoracic cage as an entity in arriving at a new prediction equation for PEFR in any locality.

The length and size of the thoracic cage are assumed to be commensurate with the height of an individual irrespective of his age and weight. The thoracic length and chest circumference were found to have positive correlation with PEFR (Salisu et al., 2007). The thoracic cage houses the lungs that handle the volume of gases during inspiration and expiration. The dimensions of the thoracic cage change proportionately with age before the epiphyses closed around 25 years of age, thereafter, remained constant up to old age. Therefore, thoracic length and size can be useful in predicting PEFR values in all ages irrespective of height and weight of an individual. This study is aimed at determining a hypothetical constant value in pregnant women living in Kura local government area of Kano state, Nigeria, which might be useful in calculating the individual PEFR value in a similar cohort in any clinical setting.

\section{MATERIALS AND METHODS}

One hundred and twenty three (123) pregnant females living in Kura local government area and its environs were employed for this research work. Kura town is situated along Zaria express way, about 30kilometers away from Kano metropolis. A random sampling method was used to select the subjects. Ethical approval was obtained from Ahmadu Bello University Ethical and Scientific Committee. An informed consent was obtained from each subject prior to the commencement of the procedures. Anthropometric measurements taken include; chest circumference at the level of $4^{\text {th }}$ intercostals space during expiration and thoracic length measured posteriorly from the root of the neck to the last rib using an inelastic measuring tape (gold fish brand superior tailoring rule chine). Peak expiratory flow rate (PEFR) on each subject was obtained using a portable Wright's peak flow meter (Clement Clark international Harlow, England). Mean values of chest circumference (CC) and thoracic length (TL) were calculated in these subjects. The product of these was equated with a product of a mean constant value and mean PEFR, i.e. means $\mathrm{CC} \times$ mean $\mathrm{TL}=$ mean $\mathrm{K} \times$ mean PERF. Therefore, mean $\mathbf{K}=$ mean $C C \times$ mean $\mathrm{TL} /$ mean PEFR. An actual value of a constant ' $\mathbf{K}$ " was obtained. $\mathbf{K}$ is in $\mathrm{min} . \mathrm{cm}^{2} /$ litre. 
The $\mathbf{K}$ value for the pregnant subjects was found to be $8.27 \mathrm{~min} . \mathrm{cm}^{2} /$ litre. This value is then considered as a representative value for pregnant females in Kura local government area. It is then equated with the product of individual values of chest circumference and thoracic length obtained on every subject during the study period to get the variant PEFR.

Statistical analysis of the data was carried out with EPI - info and Minitab software packages. One way analysis of variance was used to compare the three mean values of PEFR obtained. Linear graphs were drawn using Microsoft Excel package, to compare the observed variation of the three categories of PEFR obtained with age of the subjects. Data for plotting these graphs were generated using the prediction formula and the constant value generated from this study.

\section{RESULTS}

The mean and standard error of estimate of the three different values of PEFR are presented in Table 1 . The mean value of PEFR is statistically not significant P $>0.05$ among the three different methods adopted. Table 2 shows variation of PEFR with age.

Table 1: Mean and standard error of estimate of PEFR in Pregnant women using different methods

\begin{tabular}{llll}
\hline Variables & $\begin{array}{l}\text { Observed PEFR } \\
\mathbf{N}=\mathbf{1 2 3}\end{array}$ & $\begin{array}{l}\text { Predicted PEFR } \\
\mathbf{N}=\mathbf{1 2 3}\end{array}$ & $\begin{array}{l}\text { Variant PEFR } \\
\mathbf{N}=\mathbf{1 2 3}\end{array}$ \\
\hline Subjects Mean (SEM) & $375.20 \pm 3.12$ & $375.05 \pm 0.29$ & $375.62 \pm 3.09$ \\
\hline
\end{tabular}

PEFR values in litre per min.

Table 2: Variation of PEFR with age among the pregnant women using three different values of PEFR (in litre per min)

\begin{tabular}{|c|c|c|c|c|}
\hline $\begin{array}{l}\text { Age Range } \\
\text { (Years) } \\
\text { subjects }\end{array}$ & $\begin{array}{l}\text { Number } \\
\text { of }\end{array}$ & $\begin{array}{l}\text { Mean Observed } \\
\text { PEFR } \pm \text { SEM } \\
\mathbf{N}=\mathbf{1 2 3}\end{array}$ & $\begin{array}{l}\text { Mean Predicted } \\
\text { PEFR } \pm \text { SEM } \\
\mathbf{N}=123\end{array}$ & $\begin{array}{l}\text { Mean Variant } \\
\text { PEFR } \pm \text { SEM } \\
N=123\end{array}$ \\
\hline $15-19$ & 38 & $368.95 \pm 7.00$ & $374.34 \pm 0.37$ & $360.93 \pm 3.96$ \\
\hline $20-24$ & 48 & $379.58 \pm 4.43$ & $374.22 \pm 0.44$ & $383.95 \pm 5.07$ \\
\hline $25-29$ & 17 & $377.06 \pm 6.57$ & $375.27 \pm 0.73$ & $384.75 \pm 6.52$ \\
\hline $30-34$ & 14 & $373.57 \pm 8.93$ & $378.31 \pm 0.75$ & $366.80 \pm 10.3$ \\
\hline $35-39$ & 3 & $363.30 \pm 14.5$ & $376.62 \pm 2.21$ & $366.36 \pm 9.23$ \\
\hline $40-44$ & 1 & $390.00(\mathrm{x})^{*}$ & $385.63(x)$ & $334.82(x)$ \\
\hline $45-49$ & 1 & $350.00(x)$ & $381.91(x)$ & $418.38(x)^{*}$ \\
\hline $50-54$ & 1 & $350.00(x)$ & $369.96(x)$ & $497.70(\mathrm{x})^{*}$ \\
\hline TOTAL & 123 & $375.20 \pm 3.12$ & $375.05 \pm 0.29$ & $375.62 \pm 3.09$ \\
\hline
\end{tabular}

(x) a single subject represented the groups indicated PEFR values in litre per min.

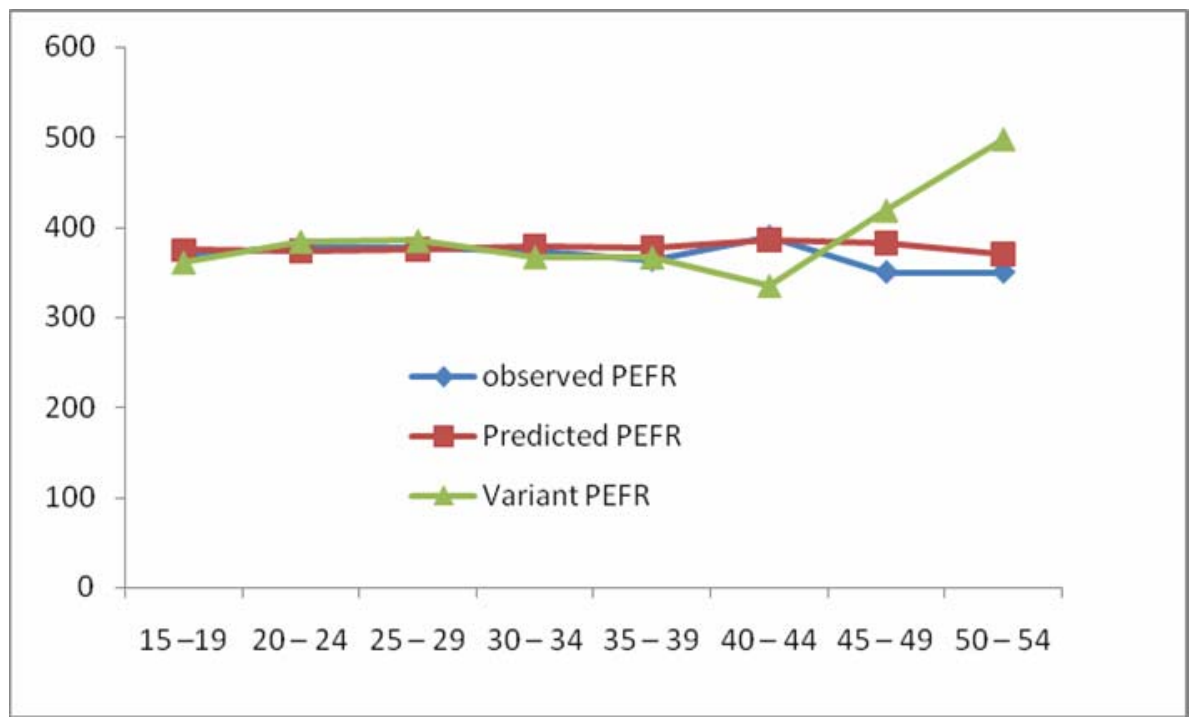

Figure 1: Variation of PEFR with age among the pregnant subjects 
Figure 1 is a graphical display of the observed variation of PEFR with age in the subjects, along with graph showing predicted and variant values of PEFR with age, using the variant formula developed in this research. Using the keys to the graph, it would be noted that, the best linear equation for the observed values in the subject produced a graph that ran closely with predicted and variant values up to 40 years of age. Thereafter, the variant formula showed an increase with increasing age, but the observed and predicted values showed a decline which agreed with what is obtained elsewhere, (Balchum et al., 1962).

\section{DISCUSSION}

It is interesting to find that there is no statistical difference $p>0.05$ between the observed PEFR value and that of predicted and variant values up to 40 years of age. The significant PEFR change was observed after the age of 40 years in single cohorts which may be due to inadequate representation in those age groups. Therefore, both the predicted and variant formulae can be applied to assess the respiratory status of an individual under a clinical setting. While conducting a research may be tedious to others and applying lengthy mathematical equation of prediction formulae may be cumbersome in the hospitals with large turn outs of patients, knowing a constant (K) value of a particular locality may simplify the approach to people with respiratory disorders especially asthma. Therefore, a two stage process is required; 1 .Conducting the actual research to get the mean Thoracic length, Chest circumference and PEFR values and 2. Equating these values, to obtain a mean hypothetical constant "K"which will represent the locality under consideration. The new constant value will be used in out patient clinics as a standard reference guide on patients who presented with respiratory diseases especially asthma to calculate their individual PEFR values. This can be achieved

\section{REFERENCES}

Balchum, O.J., Felton, J.S., Jamisson, J.N., Gaines, R.S., Clark, D.R., Owen, T. (1962): The industrial Health Committee. The Tuberculosis and Health Association of LoS Angeles country: A survey for chronic respiratory disease in an industrial city. $A m$. Rev. Respir. Dis 86: 675

Chehreh, M.N., Young, R.C., Viaene, H., Ross, C.W., Scott, R.B., (1973): Spirometric standards for healthy inner- city black children. Am J. Dis. Child. 126: 159-163

Elebute, E.A. and Femi-Pears, D., (1971): Peak flow rate in Nigeria. Anthropometric determinants and usefulness in assessment of ventilator function. Thorax, 26: 597-601.

Gregg, I., Nunn, A. J., (1989): New regression equation for predicting peak expiratory flow in adults. Bri. Med. J; 298: 1068-1074. under a clinical setting by measuring the thoracic length from the root of the neck to the last rib and chest circumference of the patient at the level of $4^{\text {th }}$ intercostals space. The PEFR value in $\mathrm{L} / \mathrm{min}$ will then be obtained by dividing the product of the thoracic length and chest circumference with the constant value of that locality. The constant "K" may differ from one locality to the other and also among the individuals because of differences in body built and thoracic cage sizes. Knowing a constant value of a particular locality will give an idea on how one locality or individual differs from one another. It will limit the generalization of prediction equations to the entire populations with dissimilar characteristics since there are racial and ethnic differences in PEFR values among individuals. From the graph it is observed that the three sets of PEFR values agree with each other up to 40 years of age. Thereafter, the variant formula showed an increase with increasing age, but the observed and predicted values showed a decline which agreed with what is obtained elsewhere, (Balchum et al., 1962). The increase in variant values observed from this study can be due to the fact that our cohorts were very young, majority of who were below the age of 30 years, therefore, giving a linear relationship between their PEFR and age. This increase may be a limitation of this variant formula beyond the age of 40 years, since decline in PEFR values is found to be faster in blacks after 40 years of age when compared with Caucasians (Balchum et al., 1962).

It can therefore be concluded that, two stage processes are required in producing a prediction PEFR equation in order to simplify future use of such equations under clinical setting. The constant " $\mathrm{K}$ " value for every locality will allow easy and quick assessment of patient with airway obstruction and also help clinicians to know how exactly one locality differs from one another.

Njoku, CH and Anah, CO., (1999): A new formula for predicting peak expiratory flow rate in adult Nigerians. Sahel Med. J. 2: 39-44.

Nku, C.O., Peters, E.J., Eshiet, A.I., Bisong, S.A., Osim, E.E., (2006): Prediction formulae for lung function parameters in females of south eastern Nigeria. Nig. J. of Physiol. sci. 21: 43-47.

Salisu, A.I., Adelaiye, A.B. and Babashani, M., (2007): A formula for predicting peak expiratory flow rate in non-pregnant and pregnant women at second and third trimesters of pregnancy in Kura local government area, Kano, Nigeria. Medwell J. Med. Sci. 5: 279- 283.

Singh, R., Singh, H.J. and Sirisinghe, R.G., (1983): FVC in Malaysians females. Jpn. J. Physiol. 42: 407-414.

Suzanne, M.B., David, A.A. and Mark, W.C., (1994): Pulmonary function test outcome in healthy Nawajo native American adolescents. $\mathrm{Am} \mathrm{J}$. Resp. Crit. Care Med. 150: 1150- 1153 